Submitted to

45th AIAA/ASME/ASCE/AHS/ASC Structures, Structural Dynamics, and Materials Conference

19-22 April 2004

Structures Sessions

\title{
DEVELOPMENT OF A FATIGUE CRACK GROWTH COUPON FOR HIGHLY PLASTIC STRESS CONDITIONS
}

\author{
Phillip A. Allen \\ Strength Analysis Group/ED22 \\ NASA Marshall Space Flight Center \\ Marshall Space Flight Center, AL 35812 \\ 256-544-1189 voice \\ 256-544-7234 fax \\ phillip.a.allen@nasa.gov \\ Pravin K. Aggarwal \\ 256-544-5345 \\ pravin.aggarwal@nasa.gov \\ Gregory R. Swanson \\ 256-544-7191 \\ greg.swanson@nasa.gov
}

\begin{abstract}
This paper presents an analytical approach used to develop a novel fatigue crack growth coupon for a highly plastic 3-D stress field condition. The flight hardware investigated in this paper is a large separation bolt that fractures using pyrotechnics at the appointed time during the flight sequence. The separation bolt has a deep notch that produces a severe stress concentration and a large plastic zone when highly loaded. For this geometry, linear-elastic fracture mechanics (LEFM) techniques are not valid due to the large nonlinear stress field. Unfortunately, industry codes that are generally available for fracture mechanics analysis and fatigue crack growth (e.g. NASGRO [1]) are limited to LEFM and are available for only a limited number of geometries. The results of LEFM based codes are questionable when used on geometries with significant plasticity. Therefore elastic-plastic fracture mechanics (EPFM) techniques using the finite element method (FEM) were used to analyze the bolt and test coupons.

A testing program was developed to verify the EPFM analysis results. Testing of fullscale flight hardware is very costly in terms of assets, laboratory resources, and schedule. Therefore to alleviate some of these problems, a series of novel test coupons were developed to simulate the elastic-plastic stress field present in the bolt. Finite element models were created to predict the state of stress with and without a crack for the actual hardware and for the laboratory
\end{abstract}


coupons. $J$ and $T$-Stress values were obtained and compared along the crack path to validate the coupon. A summary of the test coupons is given below.

The first specimen developed was a flat plate with a notch on one side as shown in Figure 1. The gage dimensions of the notched plate (NP) match a cross section of the notch region of the bolt. The specimen is pin loaded on a narrow land, and the location of the land can be varied to minimize bending effects in the notch region. Unfortunately this specimen design is very sensitive to load placement, and, therefore, a small change in load alignment results in widely varying stress fields in the notch region. In addition, placing a crack in the notch root only magnifies the stress field variance.

To reduce the alignment sensitivity of the specimen, a modified double-edge notch tension (MDENT) specimen was developed (Figure 2). This specimen has the advantage of being symmetric, which reduces bending sensitivity, while still preserving the free surface on the back face of the notch section. This specimen was an improvement over the NP specimen, but was still relatively sensitive to load alignment due to the stiffness of the transition section below the pin hole.

To reduce the alignment sensitivity of the specimen even more, the distance between the two notch sections was increased and fillets were cut into the transition section below the pin holes. Using two different fillet radii resulted in the MDENT-2 (Figure 3) and MDENT-3 (Figure 4) specimens. The moment of inertia, $I$, for the fillet section on MDENT-2 is approximately $53 \%$ that of the notched section, and $I$ for the fillet section on MDENT-3 is approximately $8 \%$ of that of the notched section. The thin fillet section acts as a flexure and therefore helps preserve the desired stress state in the notch sections.

Axisymmetric and 3-D FEM's of the flight hardware and the test specimens were created using Patran [2] and FEA-Crack [3]. The FEM's were analyzed and post-processed using ABAQUS [4].

An example of the stress field results is shown in Figure 5. In this figure the axial stress in the flight hardware is compared to the axial stress in the three MDENT specimen geometries. For each MDENT specimen the load application point is offset $\mathbf{0 . 0 5 1 2} \mathrm{in}$. towards the "right" to simulate extreme off-center loading on one side of the land. Stresses are then plotted for both the "left" and "right" notch sections. The MDENT-3 specimen is the least sensitive to load alignment and produces an axial stress distribution that reasonably matches the flight hardware stress distribution.

Figure 6 shows the variation of $J_{\text {total }}$ along the crack front for the separation bolt and for the MDENT-3 specimen with crack dimensions of $\mathrm{a}=\mathrm{c}=0.125 \mathrm{in}$. $\mathrm{J}_{\text {total }}$ distributions for proof load and flight load are given for the separation bolt. The $J_{\text {total }}$ distributions for the MDENT-3 specimen closely match the flight hardware distributions.

The crack front constraint condition for different geometries can be quantified using the non-dimensional parameter $\beta$ defined as

$$
\beta=\frac{T \sqrt{\pi a}}{K_{I}}
$$

where $T$ is the elastic $T$-stress, a is the crack depth, and $K_{I}$ is the mode I stress intensity factor [5]. Figure 7 shows the variation of $\beta$ along the crack front for the separation bolt and for the MDENT-3 specimen with crack dimensions of $\mathrm{a}=\mathrm{c}=0.125$ in. The $\beta$ values for several standard fracture test specimens are also plotted. The $\beta$ values for the MDENT-3 specimen are 
similar to the separation bolt values, thus demonstrating a comparable crack front constraint condition for the two geometries.

In summary, four test specimen iterations were analyzed in an attempt to match the elastic-plastic stress field and crack constraint conditions present in the separation bolt. Of the four test specimens analyzed, the MDENT-3 most closely approximates the stress field, $J$ values, and crack constraint conditions found in the flight hardware. The MDENT-3 is also insensitive to load misalignment and/or load redistribution during crack growth. 


\section{FIGURES}

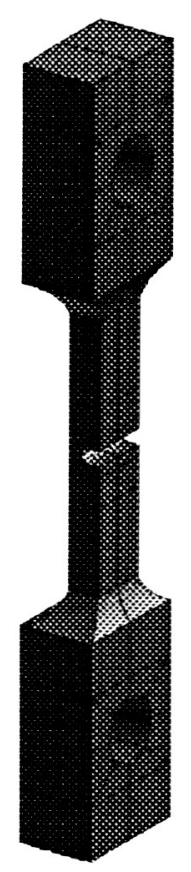

Figure 1. Illustration of Notched Plate Specimen

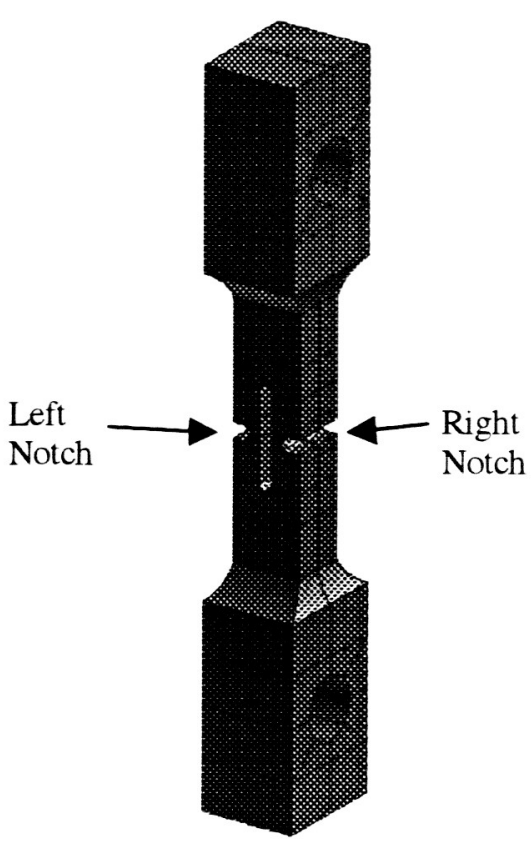

Figure 2. Illustration of MDENT Specimen 


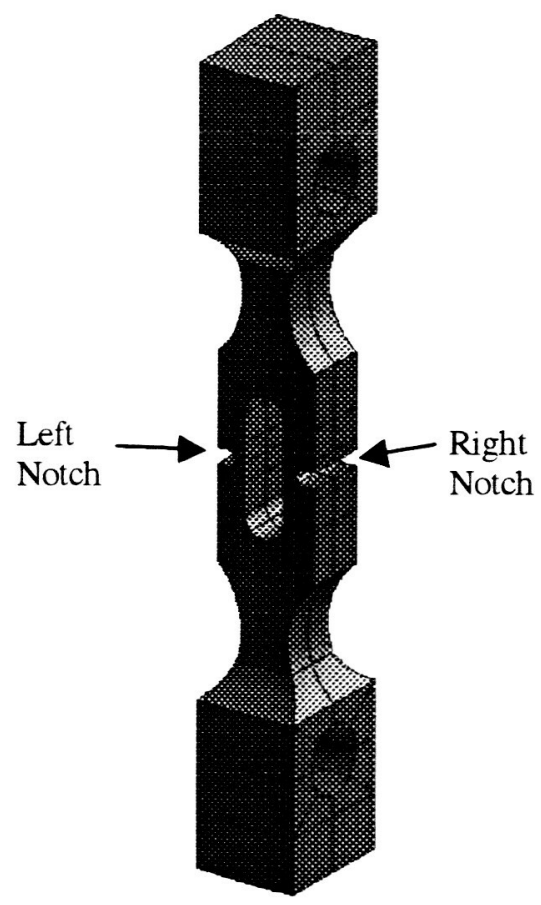

Figure 3. Illustration of MDENT-2 Specimen

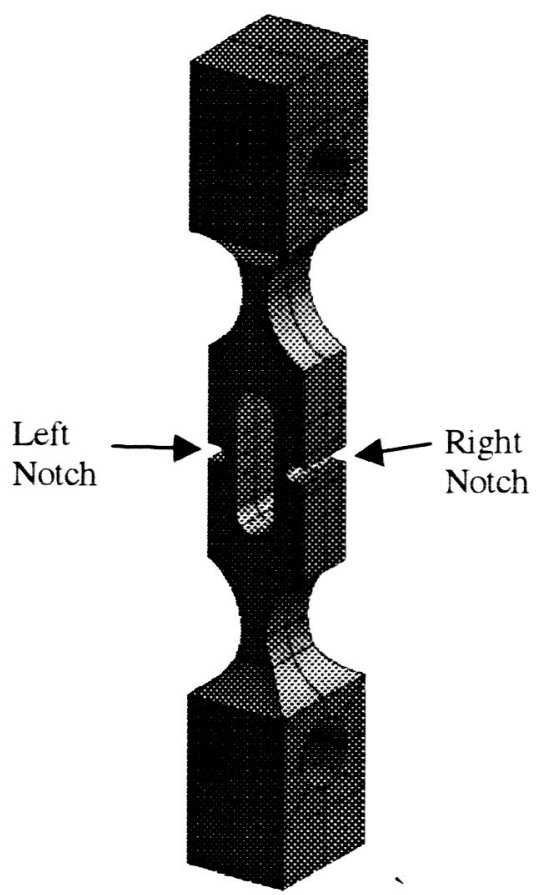

Figure 4. Illustration of MDENT-3 Specimen 


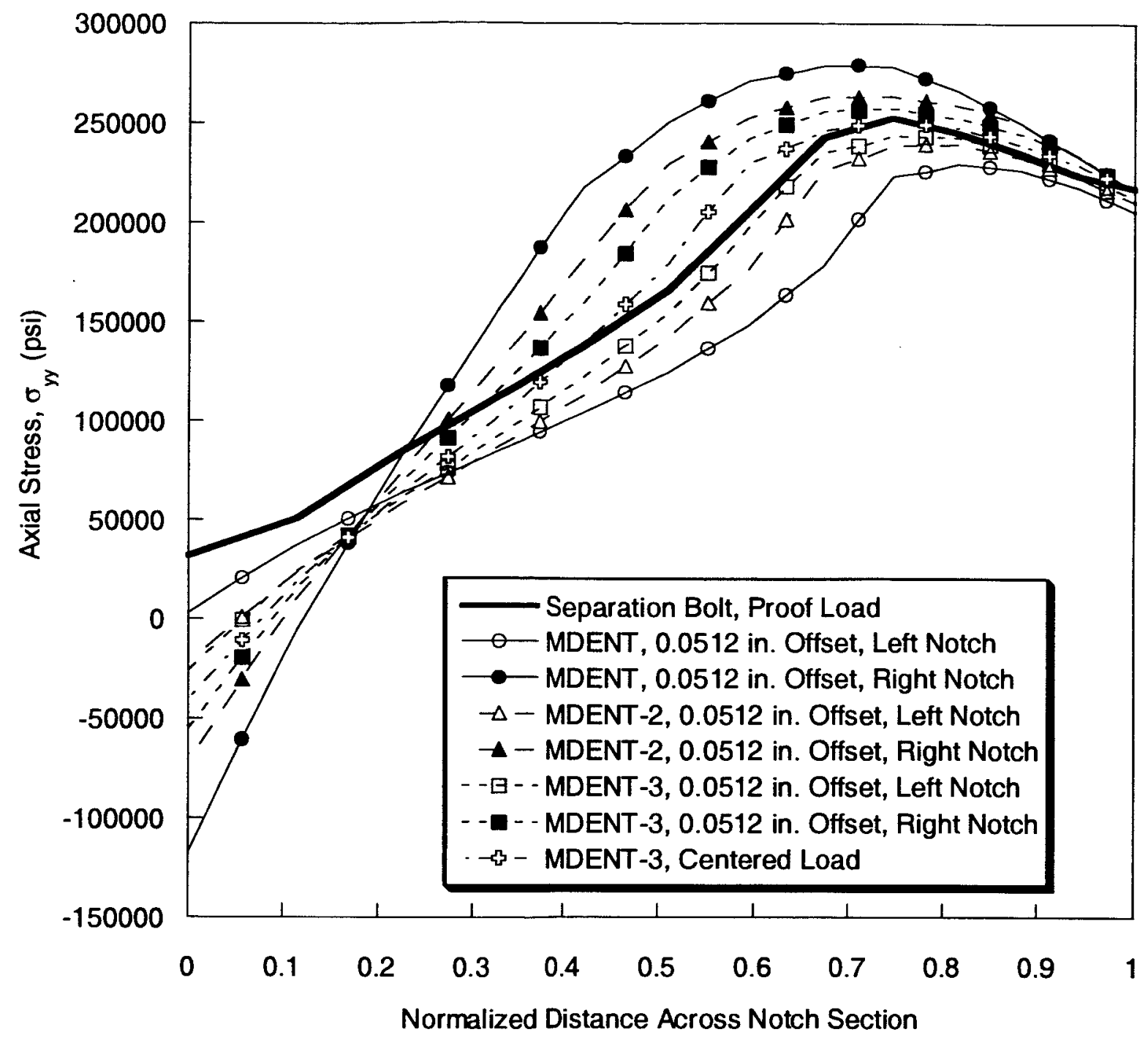

Figure 5. Axial Stress Across the Notch Section of the Separation Bolt and Three MDENT Geometries 


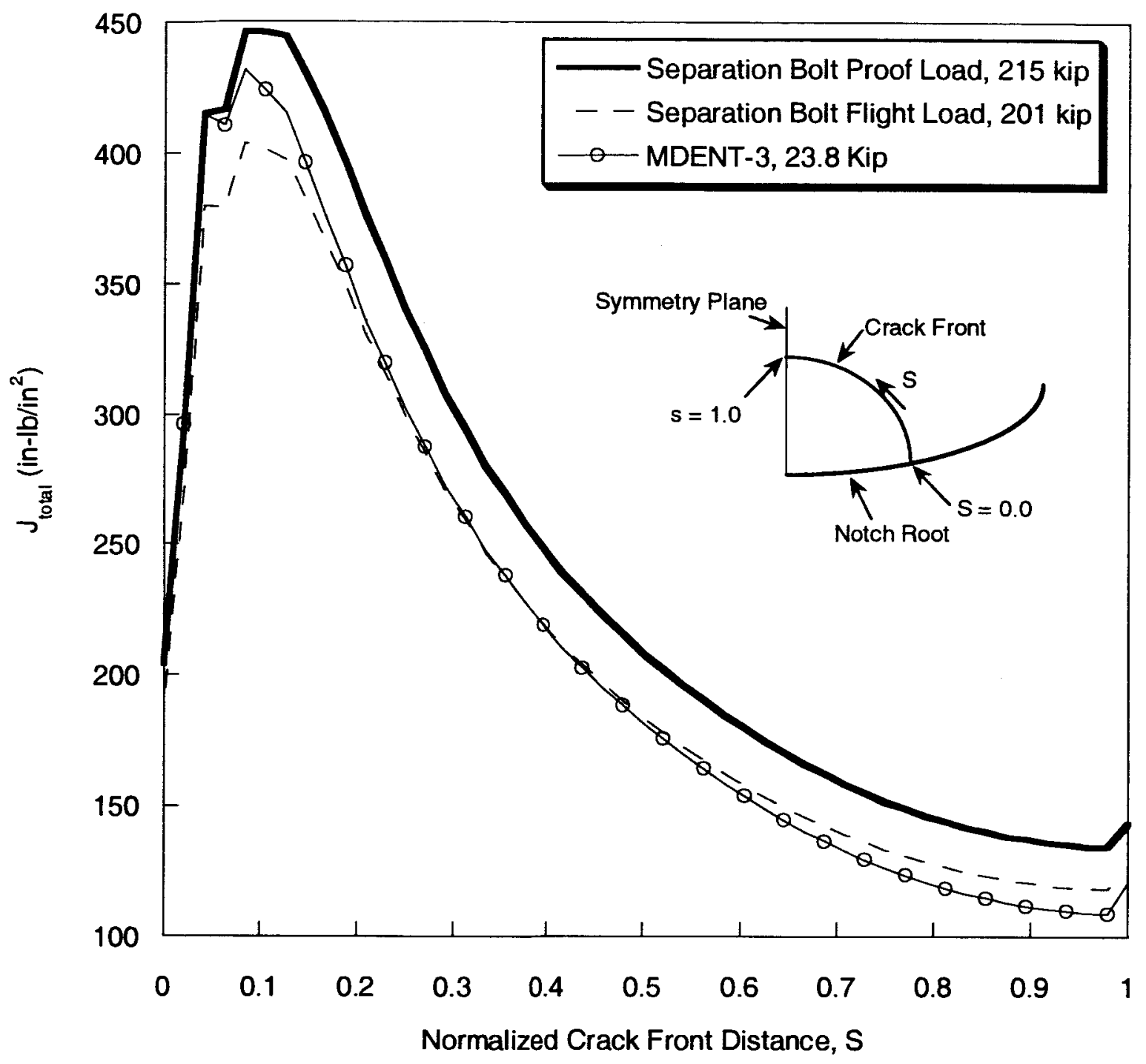

Figure 6. $J_{\text {total }}$ Along the Crack Front for the Separation Bolt and the MDENT-3 Specimen 


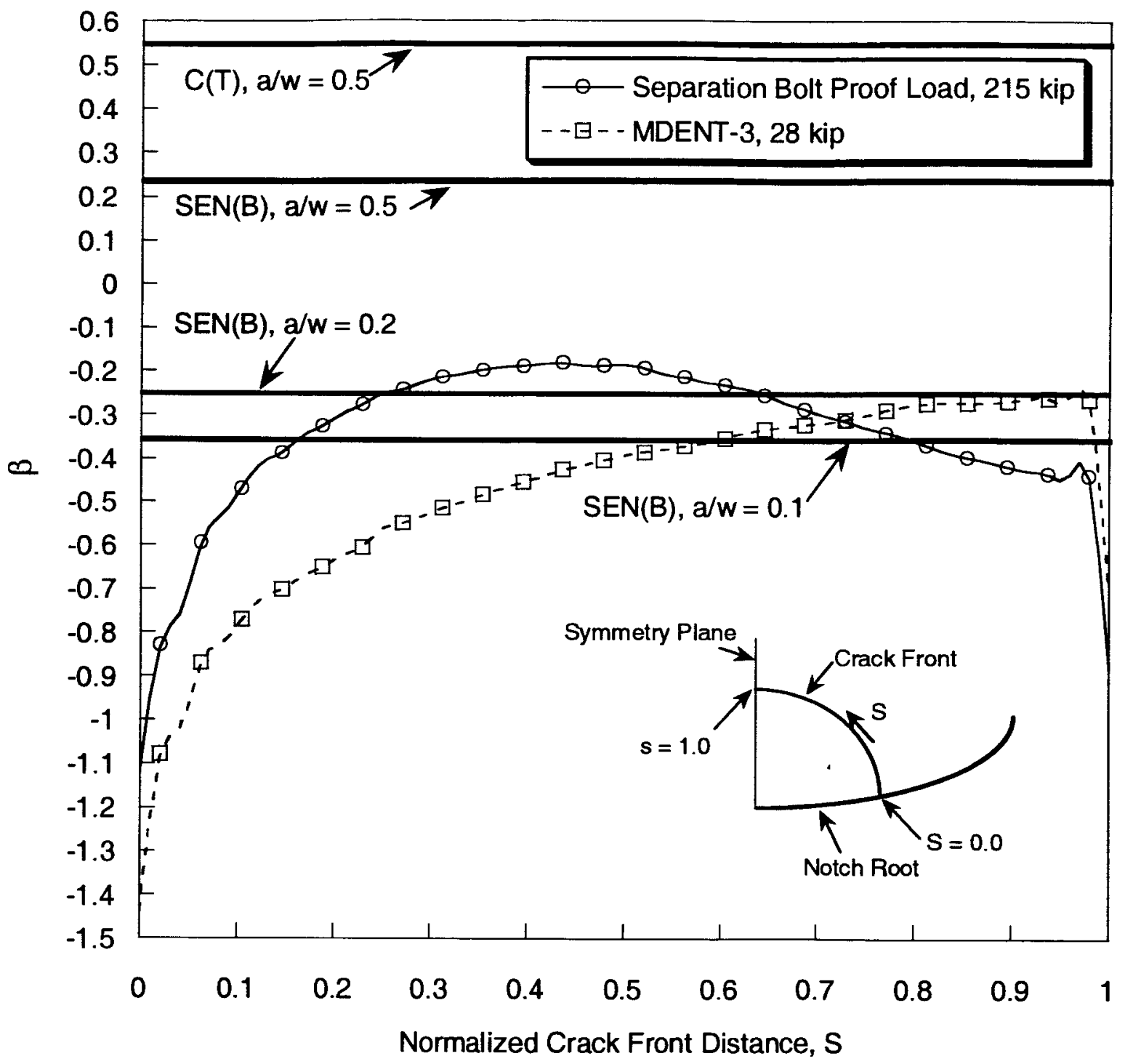

Figure 7. $\beta$ Along the Crack Front for the Separation Bolt and the MDENT-3 Specimen 


\section{REFERENCES}

1. Forman, Royce and R.C. McClung, "NASGRO 4.0, Fracture Mechanics and Fatigue Crack Growth Analysis Software, Reference Manual," Southwest Research Institute, 2002.

2. Patran Users Manual, Version 9.0, MSC Software Corporation, 2000.

3. FEA-Crack User's Manual, Version 2.5, Structural Reliability Technology.

4. ABAQUS Standard User's Manual, Version 6.2, Hibbit, Karlsson, and Sorensen, Inc., 2001.

5. Sherry, A.H., C.C. France, and M.R. Goldthorpe, "Compendium of T-Stress Solutions for Two and Three Dimensional Cracked Geometries," Fatigue and Fracture of Engineering Materials and Structures, Volume 18, No. 1, 1999, pp141-155. 